\title{
Experience of Routine Live-birth Screening for Galactosaemia in a British Hospital, with Emphasis on Heterozygote Detection
}

\author{
GRAHAM ELLIS, A. ROSS WILCOCK, and DAVID M. GOLDBERG \\ From the Department of Chemical Pathology, Royal Hospital, Sheffield
}

\begin{abstract}
Ellis, G., Wilcock, A. R., and Goldberg, D. M. (1972). Archives of Disease in Childhood, 47, 34. Experience of routine live-birth screening for galactosaemia in a British hospital, with emphasis on heterozygote detection. Results are reported of a screening programme for galactosaemia covering a period of $2 \frac{1}{2}$ years and 6415 births. The gene frequency for galactosaemia estimated from the data of the screening programme was $0 \cdot 002$. This conflicted with the known livebirth incidence of at least $1: 50,000$ during this same period. 2 of the 4 galactosaemic infants concerned died under circumstances that were preventable had they been screened at birth. The need to screen all sick infants for galactosaemia is emphasized, as is the requirement for reliable information on its incidence in Great Britain. The screening test employed (Beutler and Baluda, 1966a) seemed appropriate for this purpose. It was simple to perform and apparently accurate in galactosaemic infants. Its accuracy in detecting heterozygotes is uncertain. This test should be available in all hospitals receiving sick neonates.
\end{abstract}

Several techniques are now available which permit screening for galactosaemia. Schwarz (1963) described a method based on liberation of $\mathrm{CO}_{2}$ from blood incubated with galactose-1phosphate. A variation of this procedure measures the liberation of $\mathrm{C}^{14} \mathrm{O}_{2}$ from radioactive galactose (London, Marymont, and Fuld, 1964). Other methods utilize chromatographic separation of the labelled metabolites produced from radioactive galactose (Robinson, 1963; Tron and Milhaud, 1969). These tests are valuable diagnostic aids but are too complex for mass screening. An automated blood galactose test has been proposed (Tengström, 1969), but this is only relevant for milk-fed infants and is unlikely to permit heterozygote detection.

The most promising tests for screening purposes are those developed by Beutler. The first utilizes decolorization of methylene blue as the end-point of a reaction sequence starting with galactose-1phosphate (Beutler, Baluda, and Donnell, 1964) as shown in the Fig., and the time taken for decolorization is measured. The second and more convenient test is similar in principle. The reaction sequence is identical with the above (Fig.) but the end-point

Received 29 July 1971. comprises the fluorescence due to NADPH which may readily be observed under UV light by spotting an aliquot of the test mixture on paper after 2 hours' incubation (Beutler and Baluda, 1966a). Both tests have been validated as screening procedures (Gatti, Manfield, and Hsia, 1966; Nelson and Hsia, 1967). It has been stated that the methylene blue test provides more accurate diagnosis of heterozygotes (Camus, Farriaux, and Fontaine, 1968), but the fluorescent spot test was preferred by Beutler for mass screening because of its simplicity, especially when applied to blood dried on filter-paper, though he reported difficulties in diagnosing heterozygotes (Beutler et al., 1967).

Despite the availability of these techniques, screening for galactosaemia has never been proposed as a mandatory test in the newborn. In part, this stems from a low incidence of $1: 70,000$ estimated live-births with this condition in Great Britain (Schwarz et al., 1961), and an awareness that, despite good dietary control, propositi tend to show some degree of intellectual or emotional impairment (Hansen, 1969), possibly as a consequence of damage to the fetus in utero (Komrower and Lee, 1970). Brandt (1967) has, however, published an estimated incidence of $1: 10,000$ for Denmark, and estimates for the United States range from 


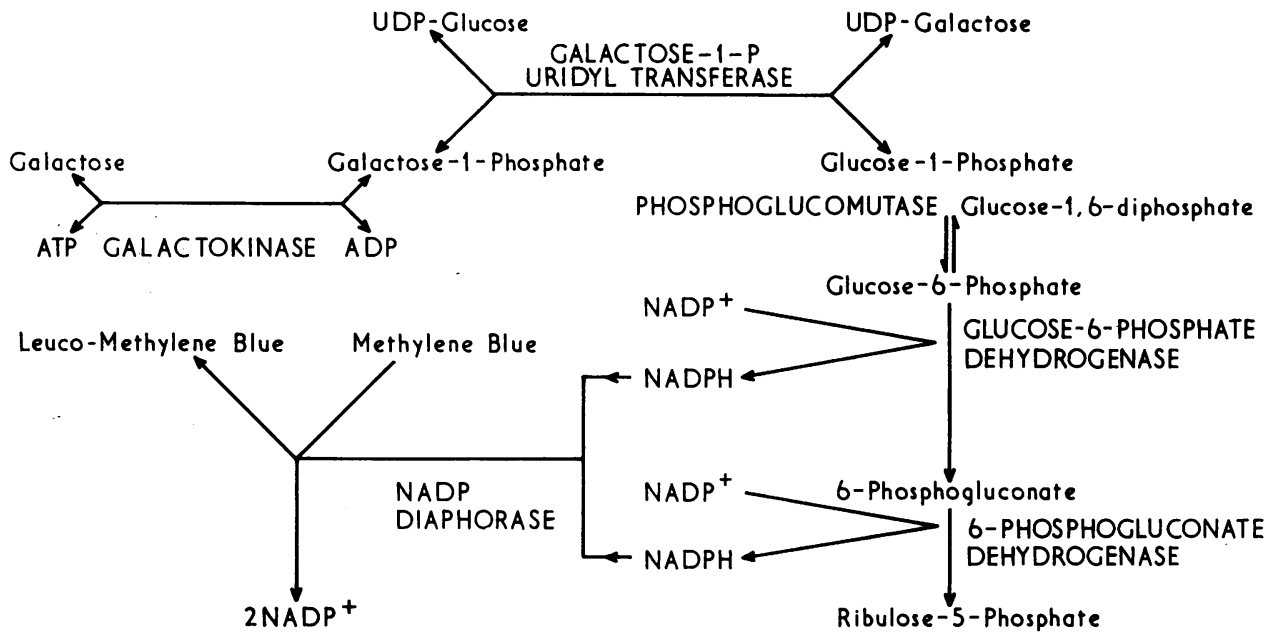

FIG.-Scheme to illustrate pathways involved in galactosaemia screening tests. NADPH and leuco-methylene blue represent the end-points of methods of Beutler and Baluda (1966a) and of Beutler et al. (1964), respectively.

$1: 18,000$ (Hansen et al., 1964) to $1: 180,000$ (Shih et al., 1971).

For some time we have been operating a routine galactosaemia screening programme for all infants born within the United Sheffield Hospitals Group. We wish to describe our experience up to the present, with the aim of providing an assessment of the method and of its place in paediatric diagnosis, as well as data that may help to throw light on the gene frequency of classical galactosaemia in our population.

\section{Materials and Methods}

All infants born at the Jessop Hospital for Women, Sheffield, were screened using cord or capillary blood taken by the clinical staff, mixed with heparin, stored at $4{ }^{\circ} \mathrm{C}$, and transmitted to this department for analysis. A single batch was run each week, so that the period of storage varied from 1 to 7 days. This protocol started on 7 November 1968 and the present report is based on 6415 births occurring between then and 8 April 1971 .

Screening test. This was essentially the method of Beutler and Baluda (1966a) with minor modifications aimed at improving the reproducibility of the technique and its application for analysis of large batches. The steps in the reaction sequence are delineated in the Fig., all of the enzymes concerned being present in normal erythrocytes.

Reagents. The following mixture was prepared: $2.4 \mathrm{ml}$ UDP-glucose, $9.5 \mathrm{mM} ; 4.8 \mathrm{ml}$ galactose-1phosphate, $27 \mathrm{mM} ; 0.36 \mathrm{ml}$ EDTA, disodium salt, $27 \mathrm{mM} ; 9.6 \mathrm{ml}$ saponin, $1 \%(\mathrm{w} / \mathrm{v}) ; 11.6 \mathrm{ml}$ water.
The mixture was accurately dispensed in aliquots of exactly $4.0 \mathrm{ml}$ and stored at $-20^{\circ} \mathrm{C}$ until required. It was then thawed, and to it were added $2.4 \mathrm{ml}$ Tris/ acetate buffer, $0.75 \mathrm{M}, \mathrm{pH} 8.0$ from a stock held at $4{ }^{\circ} \mathrm{C}$, and $0.72 \mathrm{ml}$ NADP (Boehringer Corporation London Ltd., Cat No. 15600 CNAF) $6.6 \mathrm{mM}$, freshly prepared. This provided sufficient substrate for 60 tests.

Technique. The heparinized blood, which had been stored in polythene microtubes, was thoroughly agitated using the Vortex Junior Mixer (Scientific Industries International Inc. (U.K.) Ltd.). $10 \mu 1$ were then transferred to a clean microtube appropriately labelled. The microtubes were arranged in order in a suitable microrack placed in a water bath at $37^{\circ} \mathrm{C}$. The Beckman Sanz micropipette used to deliver the blood was thoroughly flushed with $0 \cdot 15 \mathrm{M} \mathrm{NaCl}$ and then dried by air aspiration after each delivery to exclude cross-contamination.

The reaction was started by adding from another micropipette $100 \mu \mathrm{l}$ of the complete substrate mixture prewarmed to $37^{\circ} \mathrm{C}$, after which the tube was thoroughly agitated with the Vortex Junior, capped, and returned to the water bath for incubation. A fixed interval separated the beginning of the reaction in the various tubes, and exactly 1 hour later $10 \mu 1$ of the contents were removed and applied to Whatman No. 1 paper ruled to a $2 \mathrm{~cm}$ grid with each square designated for a particular blood sample. The sampling was carried out using a Beckman Sanz micropipette at exactly the same interval as separated the beginning of the reaction in adjacent tubes. A sufficient amount of the contents was aspirated to wash out any residue from the previous tube. After exactly one more hour, $10 \mu \mathrm{l}$ were withdrawn from each tube as before and applied to the paper 
adjacent to the first spot from that tube. 72 pairs of spots were applied to each sheet of paper $24 \mathrm{~cm}^{2}$. Each sheet contained samples from 2 known galactosaemic and 2 known heterozygote bloods that had been through the complete procedure as a quality control check on the reagents.

Interpretation. After being thoroughly dried, the paper was examined in a darkroom under long wave UV light. Normal blood samples fluoresce brightly at both time intervals. Blood samples from galactosaemic subjects remain dark at both intervals. Samples from galactosaemic heterozygotes and Duarte Variant homozygotes are dim at 1 hour but are indistinguishable from normals at 2 hours. Some samples associated with high $\mathrm{Hb}$ content are $\operatorname{dim}$ at 1 hour when they resemble the appearance of heterozygote samples but are clearly distinguishable from galactosaemic samples; at 2 hours they continue to present a dim appearance in contrast to heterozygote samples which then fluoresce normally; this distinction can be confirmed by examining the paper in ordinary light when the intense red spot can be easily seen. This phenomenon is due to quenching of the fluorescence by the large amount of haemoglobin present, and since fluorescence is maximal at 1 hour and quenching is independent of time, no change is evident after another hour. The effect of high $\mathrm{Hb}$ content in a heterozygote sample is to produce an appearance at both intervals not easily distinguishable from that found with a galactosaemic sample, though once again examination of the paper in natural light will reveal an intense red spot. A similar UV pattern is obtained with samples from profoundly anaemic infants, or when clotting of the specimen has occurred and led to aspiration of material containing few erythrocytes. In these instances, however, it is possible to observe, by examining the paper in natural light, that the spot is much paler than usual.

Follow-up. Whenever screening indicated that an infant was galactosaemic, or a heterozygote, a repeat sample was sought and an attempt was made to obtain venous blood from both parents. These samples were put through the screening test, and assayed quantitatively and in duplicate for erythrocyte galactose-1-phosphate uridyl transferase activity by the method of Beutler and Baluda (1966b), results being expressed as $\mu$ moles UDP-glucose consumed per hour per $\mathrm{g} \mathrm{Hb}(\mathrm{U} / \mathrm{g} \mathrm{Hb})$. In those cases where a discrepancy between the results of screening and quantitative enzyme assay was found, the sample was checked to exclude deficiencies of glucose-6-phosphate and 6-phosphogluconate dehydrogenases; no such deficiencies were encountered in the present clinical material.

\section{Results}

Accuracy of screening test. 38 samples drawn from subjects of known genetic status were screened by 5 members of the laboratory staff carrying out the test for the first time. All under- estimated the incidence of normal subjects in the material examined (Table I), and all observers $\ddot{\vec{\Rightarrow}}$ classified one or more of the heterozygotes as $\stackrel{?}{+}$ galactosaemic. This suggests that the incidence of $\bar{c}$ galactosaemics and of heterozygotes would be overestimated if classification depended on the $\frac{\bar{D}}{\vec{D}}$ results of the screening test alone.

TABLE I

Results of Screening Test by 5 Observers Carrying Out Test for First Time

\begin{tabular}{c|c|c|c}
\hline $\begin{array}{c}\text { Actual } \\
\text { Genetic } \\
\text { Status }\end{array}$ & Normal & Heterozygote & Galactosaemic \\
\cline { 2 - 3 } & 18 & 17 & 3 \\
\hline Observer 1 & 13 & 18 & 7 \\
2 & 12 & 18 & 8 \\
3 & 13 & 17 & 8 \\
4 & 11 & 23 & 4 \\
5 & 15 & 19 & 4 \\
\hline
\end{tabular}

From the subsequent results it is clear that more than half the infants originally classified as heterozygote turned out to be normal on follow-up. However, out of 45 parents, sibs, and propositi put through routine screening as part of the follow-up procedure and subsequently proven to be heterozygotes by quantitative enzyme assay, 10 escaped detection. Occasional samples contained large clots; when the results of such samples were equivocal, we tended to ascribe the phenomenon to the presence of clots and reported such cases as normal rather than recall the infant and parents for further testing. We feel that a $25 \%$ correction is needed to allow for those heterozygotes likely to have been missed through both sources of error. It is perplexing that equal mixtures of normal and galactosaemic blood never resulted in a spot indicative of a heterozygous status.

In routine practice, most normal subjects could be identified by the 1-hour spot. The 2-hour spot mainly served to pinpoint heterozygous and galactosaemic subjects, and those spots showing marked quenching due to a high $\mathrm{Hb}$ content. The improved accuracy resulting from examination at both 1 and 2 hours compared with classification of the same cases at a single time, especially where inexperienced observers are concerned, is shown in Table II.

Genetic status of population screened. Of the 6415 infants screened during this survey, representing all but 14 of the total live-births during this same period, 5 were reported as galactosaemic. Of these, 2 were ultimately classified as 
TABLE II

Influence of Time and Frequency of Reading on Accuracy of Screening Test

\begin{tabular}{|c|c|c|c|}
\hline & Normal & Heterozygote & Galactosaemic \\
\hline & 18 & 17 & 3 \\
\hline $\begin{array}{l}\text { Observer } A \\
\text { (Single reading) } \\
\text { (Read at } 1 \text { and } 2 \\
\text { hours) } \\
\text { Observer B } \\
\text { (Single reading) } \\
\text { (Read at } 1 \text { and } 2 \\
\text { hours) } \\
\text { Observer C } \\
\text { (Single reading) } \\
\text { (Read at } 1 \text { and } 2 \\
\text { hours) }\end{array}$ & $\begin{array}{r}9 \\
12 \\
2 \\
11 \\
11 \\
15\end{array}$ & $\begin{array}{l}18 \\
18 \\
26 \\
23 \\
19 \\
17\end{array}$ & $\begin{array}{r}11 \\
8 \\
10 \\
4 \\
5 \\
4\end{array}$ \\
\hline
\end{tabular}

NB: Observers had no previous experience of test.

normal and 2 as heterozygotes for galactosaemia (Table III). The fifth case was discharged home before the result was known and blood could not be obtained for re-examination, but the child was reported to be thriving at 1 year: the original specimen from this child had been mislaid for a period of 3 weeks before testing, so that loss of enzyme activity could explain the misclassification.

In all, 36 infants were reported as heterozygous for galactosaemia. Of these, 7 could not be reexamined, but all were well according to information received from their general practitioners. Of the 29 remaining, 18 were classified as normal, 9 as true heterozygotes for classical galactosaemia, and 1 each as homozygous and heterozygous for the gene of the Duarte Variant (Table IV). This classification, based mainly upon data for quantitative erythrocyte galactose-1-phosphate uridyl transferase activity of the infant and one or both parents is necessarily arbitrary because of overlap between the various genetic groups. In previous work we found that $95 \%$ of normals gave values between
13 and $30 \mathrm{U} / \mathrm{g} \mathrm{Hb}$, whereas heterozygotes ranged from 8 to $13.4 \mathrm{U} / \mathrm{g} \mathrm{Hb}$ (Ellis and Goldberg, 1969). In the classification of the present material we have included 1 infant with a value of $13.7 \mathrm{U} / \mathrm{g}$ $\mathrm{Hb}$ as a heterozygote (Case 7), and have considered values between $13 \cdot 0-17 \cdot 0 \mathrm{U} / \mathrm{g} \mathrm{Hb}$ to be compatible with the heterozygous form of the Duarte Variant (Cases 2 and 29).

Gene frequency for galactosaemia. 11 infants were established to be heterozygous for galactosaemia. If the assumption is made that all of the 8 infants who could not be followed up were also heterozygotes and if the suggested correction factor of $25 \%$ is applied to the combined figure, the probable incidence of heterozygotes in the population studied (6415 cases) becomes 25, giving a gene frequency of 0.002 and an expected live-birth incidence of $1: 250,000$. For reasons to be presented, this seems much too low an incidence.

Diagnosis of suspected cases. During the period covered by this investigation, samples were referred from 65 infants born outside the United Sheffield Hospital Group but within the Sheffield Region. Screening was carried out on the request of the paediatrician in order to confirm or exclude galactosaemia because of failure to thrive, jaundice, or presence of reducing sugar other than glucose in the urine. No heterozygotes were identified on screening among this material. A diagnosis of galactosaemia was made in 4 cases on the basis of screening followed by quantitative enzyme assays on infant and parents. 2 of these cases died, one the day after the result of the test became known, and the other before the test was carried out. The first case was jaundiced at birth: This cleared spontaneously and the child seemed. well for several weeks when jaundice recurred, accompanied by renal failure, and the child was referred to a major paediatric unit, moribund,

TABLE III

Quantitative Enzyme Results and Probable Genetic Status of Infants Initially Classified as Galactosaemic on Screening

\begin{tabular}{|c|c|c|c|c|c|c|}
\hline \multirow[t]{2}{*}{ Case No. } & \multicolumn{3}{|c|}{$\begin{array}{c}\text { Erythrocyte Galactose-1-P Uridyl Transferase } \\
\text { Activity (U/g Hb) }\end{array}$} & \multicolumn{3}{|c|}{ Probable Genetic Status* } \\
\hline & Infant & Mother & Father & Infant & Mother & Father \\
\hline $\begin{array}{l}1 \\
2 \\
3 \\
4\end{array}$ & $\begin{array}{c}11 \cdot 5 \\
10 \cdot 5 \\
21 \cdot 5\end{array}$ & $\begin{array}{l}22 \cdot 6 \\
24 \cdot 2 \\
15 \cdot 0 \\
19 \cdot 2\end{array}$ & $\begin{array}{l}12 \cdot 7 \\
18 \cdot 2 \\
13 \cdot 7 \\
18 \cdot 7\end{array}$ & $\begin{array}{l}\mathbf{H} \\
\mathbf{N} \\
\mathbf{H} \\
\mathbf{N}\end{array}$ & $\begin{array}{l}\mathbf{N} \\
\mathbf{N} \\
\mathrm{DH} \\
\mathrm{N}\end{array}$ & $\begin{array}{l}\mathbf{H} \\
\mathbf{N} \\
\mathbf{H} \\
\mathbf{N}\end{array}$ \\
\hline
\end{tabular}

${ }^{\star} \mathrm{H}=$ Galactosaemia heterozygote $\mathbf{D}=$ Duarte homozygote $; \mathrm{DH}=$ Duarte heterozygote $; \mathrm{N}=\mathrm{Normal}$. 
TABLE IV

Quantitative Enzyme Results and Probable Genetic Status of Infants Initially Classified as Galactosaemia Heterozygotes on Screening

\begin{tabular}{|c|c|c|c|c|c|c|}
\hline \multirow[t]{2}{*}{ Case No. } & \multicolumn{3}{|c|}{$\begin{array}{c}\text { Erythrocyte Galactose-1-P Uridyl Transferase } \\
\text { Activity (U/g Hb) }\end{array}$} & \multicolumn{3}{|c|}{ Probable Genetic Status } \\
\hline & Infant & Mother & Father & Infant & Mother & Father \\
\hline $\begin{array}{r}1 \\
2 \\
3 \\
4 \\
5 \\
6 \\
7 \\
8 \\
9 \\
10 \\
11 \\
12 \\
13 \\
14 \\
15 \\
16 \\
17 \\
18 \\
19 \\
20 \\
21 \\
22 \\
23 \\
24 \\
25 \\
26 \\
27 \\
28 \\
29\end{array}$ & $\begin{array}{c}12 \cdot 1 \\
11 \cdot 6 \\
79 \\
9 \cdot 9 \\
20 \cdot 6 \\
14 \cdot 4 \\
13 \cdot 7 \\
12 \cdot 4 \\
18 \cdot 0 \\
25 \cdot 4 \\
16 \cdot 0 \\
19 \cdot 0 \\
-\dagger \\
4 \cdot 4 \\
16 \cdot 6 \\
70 \\
30 \cdot 6 \\
24 \cdot 8 \\
9 \cdot 5 \\
17 \cdot 6 \\
18 \cdot 7 \\
9 \cdot 0 \\
19 \cdot 9 \\
19 \cdot 4 \\
17 \cdot 9 \\
22 \cdot 9 \\
-7 \\
15 \cdot 2\end{array}$ & $\begin{array}{r}12 \cdot 7 \\
17 \cdot 0 \\
11 \cdot 3 \\
10 \cdot 7 \\
15 \cdot 0 \\
18 \cdot 8 \\
21 \cdot 4 \\
22 \cdot 6 \\
17 \cdot 0 \\
22 \cdot 6 \\
18 \cdot 1 \\
16 \cdot 0 \\
20 \cdot 8 \\
10 \cdot 9 \\
25 \cdot 8 \\
25 \cdot 1 \\
22 \cdot 6 \\
20 \cdot 8 \\
21 \cdot 6 \\
21 \cdot 5 \\
21 \cdot 8 \\
3 \cdot 3 \\
13 \cdot 3 \\
19 \cdot 3 \\
16 \cdot 2 \\
16 \cdot 4 \\
20 \cdot 3 \\
21 \cdot 4 \\
16 \cdot 8\end{array}$ & $\begin{array}{c}22 \cdot 4 \\
15 \cdot 3 \\
17 \cdot 4 \\
26 \cdot 0 \\
- \\
20 \cdot 8 \\
12 \cdot 5 \\
8 \cdot 4 \\
20 \cdot 0 \\
24 \cdot 0 \\
15 \cdot 6 \\
- \\
19 \cdot 8 \\
16 \cdot 3 \\
24 \cdot 8 \\
- \\
- \\
- \\
28 \cdot 8 \\
10 \cdot 6 \\
22 \cdot 0 \\
22 \cdot 6 \\
21 \cdot 9 \\
25 \cdot 7 \\
19 \cdot 4 \\
12 \cdot 2\end{array}$ & 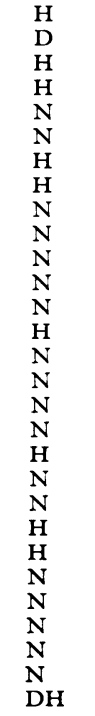 & 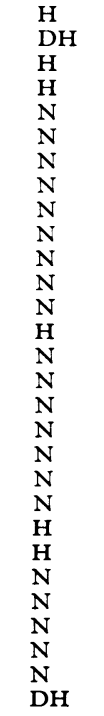 & $\begin{array}{l}\text { N } \\
D H \\
N \\
N \\
N \\
H \\
H \\
N \\
N \\
N \\
N \\
N \\
N \\
- \\
- \\
N \\
H \\
N \\
N \\
N \\
N \\
N \\
D\end{array}$ \\
\hline
\end{tabular}

${ }^{\star} \mathrm{H}=$ Galactosaemia heterozygote $; \mathrm{D}=$ Duarte homozygote $; \mathrm{DH}=$ Duarte heterozygote $; \mathrm{N}=\mathrm{Normal}$.

†Normal result on repeat of screening test.

the blood urea exceeding $400 \mathrm{mg} / 100 \mathrm{ml}$. The second case was referred from another hospital with the diagnosis of Rh-haemolytic disease and septicaemia. He had been well until the 5th day when jaundice and pyrexia developed. Laboratory results sent with the child indicated a serum bilirubin of $21.9 \mathrm{mg} / 100 \mathrm{ml}$ and blood sugar $332 \mathrm{mg} / 100 \mathrm{ml}$ (reducing sugar method). The child was moribund on admission and died within 24 hours on the 10th day. Investigations before death included a $\mathrm{Hb}$ estimation of $130 \%$ and blood sugar undetectable (glucose oxidase method). The only sib of this infant died a year before on the 4th day under unexplained circumstances. It is probable that both children would be alive today had routine screening been carried out at birth, or as soon as the infants became ill.

The total live-births in the Sheffield Region during the period of this investigation approximated 200,000. The incidence of cases known to us is thus $1: 50,000$ and we cannot exclude the possibility of other cases having been diagnosed without referral to our laboratory, or having died without diagnosis. This estimate is greatly at odds with the figure of $1: 250,000$ calculated from the results of our routine screening programme.

\section{Discussion}

The fluorescent spot test of Beutler and Baluda (1966a) appears to be a reliable test for galactosaemia homozygotes. We feel confident that no positive case has eluded detection in our series, since all infants were routinely subjected to clinical examination 6 to 8 weeks after birth. Moreover, the tests were performed almost entirely by laboratory technical staff, as many as 6 different technicians being concerned over the period described. A normal result therefore effectively serves to exclude galactosaemia. A positive result may not always be valid, though if a heterozygote response is obtained from both parents there can be little doubt about the accuracy of the diagnosis. The test requires virtually no capital outlay except a darkroom and a suitable fluorescent lamp. If the former is not available, fluorescent viewing-boxes costing about $£ 100$ will meet both requirements. 
In view of the low cost, simplicity, and accuracy of the test, it should be available in all units to which sick neonates are admitted, and should be mandatory on all such admissions. Experience of the two deaths among infants referred from district hospitals has reinforced the lesson that galactosaemia can vary considerably in the severity and type of clinical manifestations (Holzel, Komrower, and Schwarz, 1957; Hsia and Walker, 1961; Hsia, 1967; Woolf, 1968; Hansen, 1969). These may not always be recognized, and intercurrent illness may so dominate the picture as to mask the features of underlying galactosaemia or provide an apparently adequate explanation for them. It is unlikely that our experience of such cases is in any way unique, and it is noteworthy that one of the cases detected on routine screening by Kelly et al., (1970) and both cases detected by Shih et al. (1971) died within two weeks, before the result of the test had reached the clinician.

Although the reagent mixture has proved stable under our conditions, problems could arise where this is made up ad hoc for the occasional test, especially when known controls are not run in parallel. Beutler et al. (1967) found glucose-1phosphate as a contaminant of their reagents in one batch, and we experienced an occasion when a technician substituted NADPH for NADP; in both circumstances, fluorescence was obtained from all samples, including those from known galactosaemic subjects. Though large reagent packs permitting 100 tests are available commercially (Galacto-Screen, Hyland Laboratories, Los Angeles, U.S.A.), there is a need for reagents to be presented commercially in a form allowing a single, or a few determinations at a time, preferably with freezedried whole blood from normal and galactosaemic subjects, or simulated enzyme mixtures, as controls.

There is an obvious discrepancy between the data for gene frequency derived from our screening programme and the incidence of galactosaemia at birth based on cases of which we have knowledge.
The assumption that $25 \%$ of heterozygotes will be missed by our technique may be a serious underestimate, since the technician carrying out the test was usually aware that a particular batch included samples from the parents or sibs of an infant previously classified as abnormal on screening. Equal care may not have been devoted to batches comprising only samples from newborn infants being screened for the first time; there may indeed have been unconscious bias towards accepting slightly suspicious spots as normal, since all results other than those classified as normal involved further work for the staff concerned and considerable inconvenience to the parents. The only objective method for assessing the accuracy of heterozygote detection by the screening test requires parallel quantitative enzyme determinations on the same samples. On the basis of the incidence of heterozygotes we have found, this would require at least 3000 assays, which, with the quantitative method used, would take a skilled technician 1-2 years to complete. Automated fluorimetric techniques for quantitatve enzyme assay have been applied to galactosaemia screening (Sturgeon, Beutler, and McQuiston, 1967; Hochella and Hill, 1969) and should be capable of heterozygote detection. The capital cost of the required apparatus is about $£ 3000$ and the reagent costs $25 \mathrm{p}$ per test. Before the case for instituting screening programmes based on these procedures can be entertained, it is essential to know the true incidence of galactosaemia in the British population. Estimates based upon reports in the literature are presented in Table V. These show great variability, partly because they may reflect genuine alterations in gene frequency among different ethnic groups, and partly because, as in the present data, allowance has not been made (except in the report by Beutler et al., 1966, and by Mellman, Tedesco, and Feigl, 1968) for the Duarte Variant. This genetic abnormality at the galactose-1-phosphate uridyl transferase locus is, in its homozygous

TABLE V

Gene Frequency and Estimated Live-birth Incidence for Galactosaemia Reported in the Literature

\begin{tabular}{|c|c|c|c|c|c|c|}
\hline Authors & Country & Material & Numbers & Method & $\begin{array}{c}\text { Gene } \\
\text { Frequency }\end{array}$ & $\begin{array}{l}\text { Live-birth } \\
\text { Incidence }\end{array}$ \\
\hline $\begin{array}{l}\text { Mellman et al. (1968) } \\
\text { Hansen et al. (1964) } \\
\text { Kelly et al. (1970) } \\
\text { McGuinness and } \\
\text { Saunders (1967) } \\
\text { Brandt (1967) } \\
\text { Beutler et al. (1966) } \\
\text { Shih et al. (1971) }\end{array}$ & $\begin{array}{l}\text { U.S.A. } \\
\text { U.S.A. } \\
\text { U.S.A. } \\
\text { Wales } \\
\text { Denmark } \\
\text { U.S.A. } \\
\text { U.S.A. }\end{array}$ & $\begin{array}{l}\text { Healthy adults } \\
\text { Prisoners and mental patients } \\
\text { Neonates } \\
\text { Adults with lens opacity } \\
\text { Blood donors } \\
\text { General and mental hospital patients } \\
\text { Neonates }\end{array}$ & $\begin{array}{r}100 \\
268 \\
141,402 \\
340 \\
542 \\
1820 \\
374,341\end{array}$ & $\begin{array}{l}\text { Quantitative } \\
\text { Quantitative } \\
\text { Screening } \\
\text { Quantitative } \\
\text { Quantitative } \\
\text { Screening } \\
\text { Screening }\end{array}$ & $\begin{array}{l}0 \cdot 005 \\
0 \cdot 0075 \\
0 \cdot \overline{0045} \\
0 \cdot 010 \\
0 \cdot 0063 \\
-\end{array}$ & $\begin{array}{r}1: 40,000 \\
1: 18,000 \\
1: 35,000 \\
1: 50,000 \\
1: 10,000 \\
1: 25,600 \\
1: 187,000\end{array}$ \\
\hline
\end{tabular}


form, associated with reduction in enzyme activity to $50 \%$ of normal (Beutler et al., 1965, 1966), and can be distinguished with certainty from the heterozygous form of classical galactosaemia only by the appearance of abnormal bands on enzyme electrophoresis (Mathai and Beutler, 1966; Ng et al., 1969). Since galactosaemia can apparently arise as a consequence of mutation (Kelly, Dzierwa, and Baswell, 1968; Mellman et al., 1970) discrepancies are likely to occur between estimates based upon gene frequency and those based upon live-births. There is a real need to obtain authoritative data on the expected incidence of galactosaemia in this country so that a proper assessment can be made of the likely benefits of live-birth screening in relation to the resources required.

We are grateful to Drs. J. A. Black, V. Dubowitz, and R. R. Gordon and their staff for providing the samples for analysis, and to Dr. G. W. Pennington for his help in organizing the screening programme which was suggested and encouraged by Professor Arthur Jordan. Thanks are also due to the technical staff of this Department, especially Miss Andrea Wilkinson and Mr. John Towers.

\section{REFERENCES}

Beutler, E., and Baluda, M. C. (1966a). A simple spot screening test for galactosemia. Fournal of Laboratory and Clinical Medicine, 68, 137.

Beutler, E., and Baluda, M. C. (1966b). Improved method for measuring galactose-1-phosphate uridyl transferase activity of erythrocytes. Clinica Chimica Acta, 13, 369.

Beutler, E., Baluda, M., and Donnell, G. N. (1964). A new method for the detection of galactosemia and its carrier state. Fournal of Laboratory and Clinical Medicine, 64, 694.

Beutler, E., Baluda, M. C., Sturgeon, P., and Day, R. (1965). A new genetic abnormality resulting in galactose-1-phosphate uridyltransferase deficiency. Lancet, 1, 353.

Beutler, E., Baluda, M. C., Sturgeon, P., and Day, R. W. (1966). The genetics of galactose-1-phosphate uridyl transferase deficiency. Fournal of Laboratory and Clinical Medicine, 68, 646.

Beutler, E., Irwin, H. R., Blumenfeld, C. M., Goldenburg, E. W., and Day, R. W. (1967). Field test of galactosemia screening methods in newborn infants. Fournal of the American Medical Association, 189, 501.

Brandt, N. J. (1967). Frequency of heterozygotes for hereditary galactosaemia in a normal population. Acta Genetica et Statistica Medica, 17, 289.

Camus, B., Farriaux, J. P., and Fontaine, G. (1968). Le dépistage des hétérozygotes de la galactosémie. Annales de Biologie Clinique, 26, 1223.

Ellis, G., and Goldberg, D. M. (1969). The enzymological diagnosis of galactosaemia. Annals of Clinical Biochemistry, 6, 70.

Gatti, R. A., Manfield, P., and Hsia, D. Y. Y. (1966). Screening newborn infants for galactosemia. Fournal of Pediatrics, 69, 1126.

Hansen, R. G. (1969). Hereditary galactosaemia. Fournal of the American Medical Association, 208, 2077.

Hansen, R. G., Bretthauer, R. K., Mayes, J., and Nordin, J. H. (1964). Estimation of frequency of occurrence of galactosemia in the population. Proceedings of the Society for Experimental Biology and Medicine, 115, 560
Hochella, N. J., and Hill, J. B. (1969). Fluorometric screening procedure for galactosemia utilizing the Autoanalyzer. Clinical Chemistry, 15, 949.

Holzel, A., Komrower, G. M., and Schwarz, V. (1957). Galactosemia. American fournal of Medicine, 22, 703.

Hsia, D. Y. Y. (1967). Clinical variants of galactosemia. Metabolism: Clinical and Experimental, 16, 419.

Hsia, D. Y. Y., and Walker, F. A. (1961). Variability in the clinical manifestations of galactosemia. Fournal of Pediatrics, 59, 872.

Kelly, S., Dzierwa, C., and Baswell, D. (1968). Another biochemical variant of galactosemia. Experimental and Molecular Pathology, 8, 23.

Kelly, S., Katz, S., Burns, J., and Boylan, J. (1970). Screening for galactosemia in New York State. Public Health Reports, 85, 575.

Komrower, G. M., and Lee, D. H. (1970). Long-term follow-up of galactosaemia. Archives of Disease in Childhood, 45, 367.

London, M., Marymont, J. H., Jr., and Fuld, J. (1964). A microdiffusion test for congenital galactosemia utilizing galactose1-C14. Pediatrics, 33, 421.

McGuinness, R., and Saunders, R. A. (1967). Erythrocyte galactose-1-phosphate uridyl transferase and glucose-6phosphate dehydrogenase activity in the population of the Rhondda Fach. Clinica Chimica Acta, 16, 221.

Mathai, C. K., and Beutler, E. (1966). Electrophoretic variation of galactose-1-phosphate uridyltransferase. Science, 154, 1179.

Mellman, W. J., Allen, F. H., Jr., Baker, L., and Tedesco, T. A. (1970). Direct evidence of mutation at the locus for galactose-1 phosphate uridyl transferase. Pediatrics, 45, 672.

Mellman, W. J., Tedesco, T. A., and Feigl, P. (1968). Estimation of the gene frequency of the Duarte variant of galactose-1phosphate uridyl transferase. Annals of Human Genetics, 32, 1 .

Nelson, K., and Hsia, D. Y. Y. (1967). Screening for galactosemia and glucose-6-phosphate dehydrogenase deficiency in newborn infants. Fournal of Pediatrics, 71, 582.

Ng, W. G., Bergren, W. R., Fields, M., and Donnell, G. N. (1969). An improved electrophoretic procedure for galactose-1phosphate uridyl transferase: demonstration of multiple activity bands with the Duarte variant. Biochemical and Biophysical Research Communications, 37, 354.

Robinson, A. (1963). The assay of galactokinase and galactose-1phosphate uridyl transferase activity in human erythrocytes: a presumed test for heterozygous carriers of the galactosemic defect. Fournal of Experimental Medicine, 118, 359.

Schwarz, V. (1963). Diagnostic test for hereditary galactosaemia. Association of Clinical Pathologists, Broadsheets, 45.

Schwarz, V., Wells, A. R., Holzel, A., and Komrower, G. M. (1961). A study of the genetics of galactosaemia. Annals of Human Genetics, 25, 179.

Shih, V. E., Levy, H. L., Karolkewicz, V., Houghton, S., Efron, M. L. Isselbacher, K. J., Beutler, E., and MacCready, R. A. (1971). Galactosemia screening of newborns in Massachusetts. New England fournal of Medicine, 284, 753.

Sturgeon, P., Beutler, E., and McQuiston, D. (1967). Automated method for screening for galactosemia. In Technicon Symposium, 1966, p. 75. Mediad, New York.

Tengström, B. (1969). Automated blood galactose analysis as a screening method for galactosaemia in milk-fed newborns. Scandinavian fournal of Clinical and Laboratory Investigation, 23, 197.

Tron, P., and Milhaud, G. (1969). Galactosémie: métabolisme du galactose ${ }^{14} \mathrm{C}$ dans les cellules sanguines. Application au dépistage des hétérozygotes. Revue Française d'Etudes Cliniques et Biologiques, 14, 12.

Woolf, L. I. (1968). Recent studies on galactosaemia, phenylketonuria and homocystinuria. Proceedings of the Nutrition Society, 27, 88

Correspondence to Dr. D. M. Goldberg, Department of Chemical Pathology, Royal Hospital, Sheffield S1 3SR.

.

